\title{
BUDISTAS EN MÉXICO. UNA APROXIMACIÓN DESDE LAS ESTADÍSTICAS CENSALES ${ }^{1}$
}

\author{
Ezer R. May May²
}

Resumen: Los estudios del budismo en México son escasos, apenas se encuentra en su fase embrionaria. Por tanto, acercarnos a los datos censales resulta básico e imprescindible para analizar algunos aspectos de la implantación de la religión budista. Para cumplir este objetivo, expongo el perfil socio-demográfico de los budistas. Con base en las estadísticas reflexiono en torno a la identidad e identificación religiosa desde una perspectiva histórica, así también sobre su distribución geográfica, nativización, feminización y otras tendencias demográficas con el fin de entender sus implicaciones sociales. A pesar de las deficiencias del método censal para explicar los fenómenos religiosos, es una ventana que se puede abrir para tener un acercamiento al budismo en México, religión no considerada hasta ahora como significativa en términos cuantitativos.

Palabras clave: Budismo; Estadísticas; Censo; Identidad; México.

\section{BUDDHISTS IN MEXICO. AN APPROACH FROM CENSUS STATISTICS}

\begin{abstract}
The studies of Buddhism in Mexico are scarce, is just in its embryonic phase. Therefore, approaching to census data is basic and essential to analyze some aspects of the implantation of the Buddhist religion. To fulfill this objective, I expose the socio-demographic profile of Buddhists. Based on the statistics, I reflect on identity and religious identification from a historical perspective, as well as on geographical distribution, nativization, feminization and other demographic

1 El presente artículo es una versión ampliada y revisada de la ponencia Algunas tendencias de la población budista en México. Censos 2000 y 2010 presentada en el XVIII Encuentro de la Red de Investigadores del Fenómeno Religioso en México, realizada el 15-17 de abril de 2015 en Mérida, Yucatán.

2 Maestro en Historia por el Centro de Investigaciones y Estudios Superiores en Antropología Social, y Antropólogo social por la Universidad Autónoma de Yucatán, México. E-mail: ezer.may@hotmail.com.
\end{abstract}

Debates do NER, Porto Alegre, Ano i 9, N. 35, P. 237-270, Jan./Jul. 20 i 9 
trends in order to understand their social implications. In spite of the deficiencies of the census method to explain the religious phenomena, it is a window that can be opened to have an approach to Buddhism in Mexico, religion hitherto not considered as significant in quantitative terms.

Keywords: Buddhism; Statistics; Census; Identity; Mexico.

\section{INTRODUCCIÓN}

En México se conoce al Budismo más como sistema de pensamiento y 'doctrina' que como conjunto de prácticas religiosas apropiadas e inmersas en una sociedad y cultura específica. Los antropólogos, sociólogos e historiadores de la religión en el referido país se han interesado mayormente por los movimientos pentecostales, para-protestantes, ${ }^{3}$ mínimamente por el Islam, y recientemente por los llamados grupos Nueva Era. El budismo y el hinduismo no han sido considerados - hasta ahora - entre las ciencias sociales mexicanas como objetos de estudio legítimos por su reducido número de adherentes ${ }^{4}$ y por ser tangenciales del fenómeno New Age.

Existe una imprecisión fundamental en la generalización de la asociación del Budismo con el New Age; este último, se define como una red de grupos doctrinalmente dispares y carentes de liderazgo único, en contraste con la existencia de agrupaciones budistas no interconectadas en una red informal y con líderes específicos, e inclusive, exclusivos que guían la vida y

3 En la tipología del protestantismo en México se clasifica como pentecostales a las Asambleas de Dios, Iglesia Apostólica de la Fe en Cristo Jesús, la Luz del Mundo, etcétera; y entre los para-protestantes, a los Testigos de Jehová, la Iglesia de Jesucristo de los Santos de los Últimos Días (Mormones) y los Adventistas del Séptimo Día (Fortuny, 2001)

${ }^{4}$ Un sociólogo español decía, “[...] los grupos de origen oriental, hay que afirmar que su presencia en América Latina es completamente irrelevante. [...] Probablemente nunca serán fenómenos masivos" (Valderrey, 1998, p. 28). Esta visión es la que aún permea en la sociología y antropología en México. 
práctica religiosa. En consecuencia, en el fondo se dejan de lado o se ignoran los tres pilares: el Buda, el Dharma y la Sangha .

Los trabajos que abordan al budismo en México como práctica religiosa son escasos, podemos mencionar los realizados en torno a la Soka Gakkai (Okubo, 1991; Inoue, 2003; May, 2015; 2016), Jodo Shinshu (Morales, 2002), Zen (Fujiwara, 1998; Morales, 2006) y Vipassana (Hernández, 2012). Aun así no contamos con un panorama general del perfil de los budistas en México, el cual nos permita dilucidar las tendencias en su implantación y adopción, o contemplar cuál sería el rostro de un budismo mexicano.

El carácter "liquido" de la presencia de los practicantes budistas en Occidente hace difícil conseguir una imagen precisa y nítida de esta religión. Por lo que algunos investigadores, como en el caso de Espańa, han optado por visibilizar al budismo a través del registro de su patrimonio arquitectónico, como sus centros, monasterios, asociaciones y pagodas; es decir, no contabilizándolo en relación a la cantidad de practicantes o 'creyentes' (Diez de Velasco, 2018). En ausencia de datos estadísticos suficientes, esta perspectiva metodológica resulta fructífera y necesaria para efectuar análisis confiables.

Dicha inseguridad ha ocasionado la desidia en el uso de datos censales para el estudio y aproximación de grupos religiosos minoritarios, exóticos y poco conocidos. Los principales argumentos son, la imprecisión del método censal, la poca preparación de los encuestadores para identificar correctamente la afiliación religiosa, la inadecuada formulación de las preguntas y la errónea categorización/clasificación de las religiones por motivos de desconocimiento. Por otra parte, para el caso del Budismo en México se debe a que la cantidad absoluta no es representativa, es menor a $1 \%$ respecto al total nacional. Todas estas limitaciones no se niegan; pero se necesita reconocer que todo método de recolección de información tiene sus propios desperfectos.

5 Algunos trabajos que realizan este tipo de lectura son Gutiérrez (1996), Berges et al. (2006), y De la Torre y Gutiérrez (2016). 
A reservas de estas deficiencias metodológicas de los censos, me parece imprescindible recuperar la riqueza de la información numérica ofrecida por los microdatos de la Institución Nacional de Estadística Geografía e Informática (INEGI) de México ${ }^{6}$. Si bien no revela la condición exacta, sí dilucida las tendencias en torno a esta religión poco explorada en México.

Por tanto, en este artículo expongo el perfil de los budistas en México considerando variables demográficas como sexo, edad, lugar de nacimiento, región geográfica, etcétera. Así mismo, me propongo reflexionar en torno a la identidad religiosa, comprender la expansión geográfica del Budismo e indagar sobre cuál es el rostro social de esta religión de origen exógeno. No obstante dada la naturaleza del objetivo propuesto, la pretensión es generar más preguntas para futuras pesquisas que respuestas concluyentes.

\section{PENSANDO LAS IDENTIDADES E IDENTIFICACIONES BUDISTAS}

Uno de los principales argumentos en contra de los censos es la sospecha del auto-reconocimiento del sujeto referente a su adscripción religiosa. Las afiliaciones al Budismo no son la excepción para no dudar.

Para el caso de México existe una alta probabilidad de que, en los sujetos contabilizados como budistas convivan en sus creencias y prácticas diferentes tradiciones religiosas o distintas escuelas budistas; de tal modo que los sub-registros pueden ser cuantiosos. El presidente de la Casa Tíbet, Marco Antonio Karam menciona que:

[...] si por budista interpretamos personas que tienen algún tipo de vínculo o interés espiritual o cultural etcétera en esta tradición, pues podría decir que un censo de esta naturaleza se queda corto. Hay mucho más. [...] Pero si por

6 Agradezco mucho al personal del INEGI por la facilitación de los microdatos del censo de 2000. También a la Dra. Patricia Fortuny y al Dr. Carlos Macías del CIESAS-Peninsular por intermediar institucionalmente esta solicitud. 
budistas entendemos personas que realmente practican y están comprometidas con esta particular tradición espiritual en un sentido tradicional de la palabra de lo que significa ser budista entonces diría que ese censo es excesivo (Marco A. Karam, entrevista oral, 13/10/2014) ${ }^{7}$.

En esta diferencia que refiere el líder budista mexicano se puede entender a los primeros como simpatizantes y a los segundos como los comprometidos. Thomas Tweed nombró a los simpatizantes como Nightstand Buddhists, quienes leen libros de maestros budistas Zen por atracción cultural (Tweed, 1999). Pero, ¿qué significa estar comprometido con el Budismo o práctica budista? ¿Qué tipo de compromiso se requiere para ser reconocido como budista? Tal vez sea trivial decir, que aquel que llamamos simpatizante siente el compromiso consigo mismo de realizar asiduamente dichas lecturas.

Gráfica 1 - Población budista en México (1895-2010)

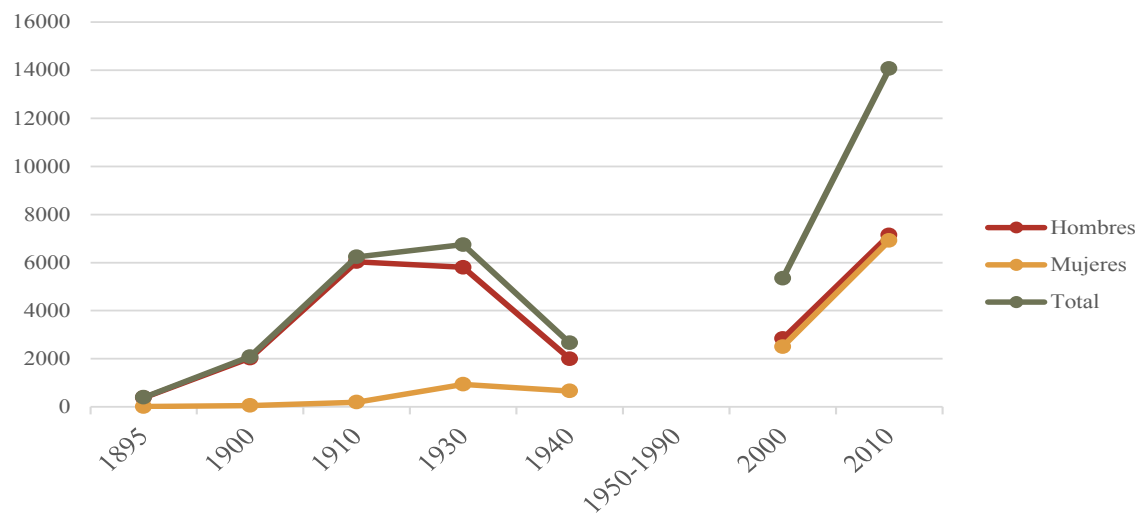

Muchos investigadores han reflexionado en torno a quién podemos considerar budista. ¿Se puede llamar a alguien budista en su comportamiento, perspectiva, cosmovisión e ideología? $\mathrm{O}$ ¿porque confiesa tomar refugio en los tres tesoros del budismo: Buda, Dharma, Sangha? (Danyluk, 2003, p. 127) ¿Quién debe asignar dicho reconocimiento? ¿A caso el maestro, el

7 Entrevista con Marco Antonio Karam realizada por el autor.

Debates do NER, Porto Alegre, Ano i 9, N. 35, P. 237-270, Jan./Jul. 20 i 9 
monje, el académico o el sujeto mismo? Del lado subjetivo, también nos encontramos con dificultades cuando el mismo individuo no está seguro si aún es católico, protestante y ahora budista o si puede decirse budista cuando práctica y cree en otras tradiciones religiosas. Usarski menciona que la inseguridad en el auto-reconocimiento aparece en parte por ausencia de criterios que lo faciliten para el sujeto, debido a la misma diversidad de estructura y apertura organizacional de los grupos budistas (Usarski, 2009, p. 111). Ante el escenario actual de bricolajes religiosos, multi-religiosidad y de condición de minoría resulta significativo auto-reconocerse como budista frente a los encuestadores.

En la gráfica 1, se observa la población budista registrada desde el primer censo de 1895 hasta el último de 2010 con un vacío entre 1950 y 1990. Este vacío nos permite, para fines analíticos, dividir nuestra serie histórica en dos momentos.

\section{Primer momento}

Entre 1895 y 1910, la población budista tuvo un progresivo crecimiento y uno mínimo en 1930; el declive es notorio entre este último año y 1940. La gran parte de los que se auto-identificaron como budistas son de origen asiático: chinos y japoneses. Los primeros comienzan a llegar desde 1875 y los segundos desde 1897, siendo mayoría la población china.

En el periodo revolucionario (de 1910 en adelante) se gestaron varios movimientos xenófobos en aras de proteger a la nación de las ideas y costumbres extranjeras. Entre ellos podemos referir al movimiento anti-chino, el cual organizó varios ataques a comunidades completas. El caso más conocido es la matanza de 303 chinos en mayo de 1911 en Torreón, Coahuila. La persecución estuvo en gran manera determinada por la imagen de un Oriente retrasado e inferior (Taboada, 1998; Hincapié, 2001). Por tanto, el descenso de la población budista estuvo marcada por la persecución de chinos, basta mencionar su importancia cuando se registran 947 chinos y 400 budistas en 1895, 2,729 y 2,090 respectivamente para el año de 1900 . 
Tanto los inmigrantes chinos como los japoneses se aglutinaron en las entidades de la zona norte de México, que como se observa en el cuadro 1, es la región en donde también se concentró la mayor cantidad de budistas.

Cuadro 1 - Población budista en México por regiones

\begin{tabular}{ccccc}
\hline Regiones & 1895 & 1900 & 1910 & 1940 \\
\hline Estados del Centro & 56 & 266 & 707 & 546 \\
Estados del Norte & 253 & 1,235 & 3,734 & 1,204 \\
Estados del Golfo & 21 & 276 & 1,256 & 544 \\
Estados del Pacífico & 138 & 313 & 1,114 & 299 \\
\hline
\end{tabular}

Fuente: Elaboración propia con base en los censos $1^{\circ}, 2^{\circ}, 3^{\circ}$ y $5^{\circ}$ del INEGI, las divisiones regionales se modificaron mínimamente del propuesto por el mismo censo. Centro: Aguascalientes, Distrito Federal, Durango, Guanajuato, Hidalgo, México, Morelos, Puebla, Querétaro, San Luis Potosí, Tlaxcala y Zacatecas. Norte: Baja California Norte, Coahuila, Chihuahua, Nuevo León y Sonora. Golfo: Campeche, Tabasco, Tamaulipas, Veracruz, Yucatán. Pacífico: Colima, Chiapas, Guerrero, Jalisco, Michoacán, Oaxaca, Sinaloa y Nayarit.

Aunque como se señaló, la cantidad de budistas es menor en comparación de la población de procedencia china, por lo que se sabe muy poco sobre las creencias de esta población; empero, se puede deducir que en su mayoría eran confucianos dado que en este periodo Japón invadía China; por lo que China, que se había mantenido fuerte en el Confucianismo, veía al Budismo como el referente simbólico del enemigo nipón.

Para el caso de los japoneses, su presencia fue menos notoria pero con una mayor aceptación pública en México debido a su caracterización como población afable y valiente. En su mayoría se congregaron en la región norte por su cercanía con Estados Unidos. Desde la primera ola de inmigrantes se trajo el budismo Jodo Shinshu perteneciente a la Honpa Hongwanji (Okubo, 1991) y en su mayoría importaron el Sintoísmo, tal como las manifestaciones externas y públicas lo evidenciaron: la salutación al sol y la puesta del altar dedicado a sus antepasados. Entre 1890 y 1940, de los 401 registros de entrada de japoneses a México, 343 declararon ser 
budistas (Ota, 1982, p. 131, p. 140). La Segunda Guerra Mundial fue el evento que afectó su presencia en México. Muchos japoneses residentes en México fueron bloqueados por Estados Unidos y expulsados a petición de este mismo país.

En este sentido, queda claro que en este primer momento las identificaciones como budistas estuvieron determinadas por el origen étnico y la condición de inmigrantes. Los eventos bélicos influyeron en su declive, y la concentración en la región norte se debió a su interés por residir en el país norteamericano.

\section{Segundo momento}

Ahora damos un salto al siglo XXI, 2000-2010. Me parece importante recordar la relevancia del crecimiento de personas que optan por reconocerse primariamente como budistas. De 5,346 registrados en 2000 ascendió a 14,062 budistas en 2010; es decir, más del doble.

Cuadro 2 - Budistas en México por Estado 2000-2010

\begin{tabular}{ccccc}
\hline Estado & 2000 & 2010 & $\begin{array}{c}\text { Tasa de } \\
\text { crecimiento }\end{array}$ & Tasa anual \\
\hline Aguascalientes & 181 & 268 & 48.07 & 4.81 \\
Baja California & 229 & 1,512 & 560.26 & 56.03 \\
Baja California Sur & 42 & 128 & 204.76 & 20.48 \\
Campeche & 10 & 11 & 10.00 & 1.00 \\
Coahuila & 56 & 229 & 308.93 & 30.89 \\
Colima & 14 & 42 & 200.00 & 20.00 \\
Chiapas & 40 & 150 & 275.00 & 27.50 \\
Chihuahua & 53 & 174 & 228.30 & 22.83 \\
Distrito Federal & 1,936 & 4,550 & 135.02 & 13.50 \\
Durango & 12 & 43 & 258.33 & 25.83 \\
Guanajuato & 159 & 484 & 204.40 & 20.44 \\
Guerrero & 24 & 58 & 141.67 & 14.17
\end{tabular}




\begin{tabular}{|c|c|c|c|c|}
\hline Hidalgo & 23 & 93 & 304.35 & 30.43 \\
\hline Jalisco & 523 & 1,099 & 110.13 & 11.01 \\
\hline México & 606 & 1,452 & 139.60 & 13.96 \\
\hline Michoacán & 77 & 297 & 285.71 & 28.57 \\
\hline Morelos & 122 & 296 & 142.62 & 14.26 \\
\hline Nayarit & 9 & 91 & 911.11 & 91.11 \\
\hline Nuevo León & 203 & 506 & 149.26 & 14.93 \\
\hline Oaxaca & 35 & 107 & 205.71 & 20.57 \\
\hline Puebla & 66 & 232 & 251.52 & 25.15 \\
\hline Querétaro & 63 & 293 & 365.08 & 36.51 \\
\hline Quintana Roo & 119 & 389 & 226.89 & 22.69 \\
\hline San Luis Potosí & 27 & 94 & 248.15 & 24.81 \\
\hline Sinaloa & 26 & 190 & 630.77 & 63.08 \\
\hline Sonora & 48 & 338 & 604.17 & 60.42 \\
\hline Tabasco & 9 & 44 & 388.89 & 38.89 \\
\hline Tamaulipas & 143 & 85 & -40.56 & -4.06 \\
\hline Tlaxcala & 6 & 29 & 383.33 & 38.33 \\
\hline Veracruz & 284 & 410 & 44.37 & 4.44 \\
\hline Yucatán & 187 & 335 & 79.14 & 7.91 \\
\hline Zacatecas & 14 & 33 & 135.71 & 13.57 \\
\hline $\begin{array}{c}\text { Población budista } \\
\text { nacional }\end{array}$ & 5,346 & 14,062 & 163.04 & 16.30 \\
\hline
\end{tabular}

Fuente: Elaboración propia con base en los microdatos del censo 2000 y los tabulados de 2010, INEGI.

En el cuadro 3 se observa que el valor absoluto de la población budista nacional no es significativa, en el 2000 ésta población representó el 0.006\% respecto a la población nacional total y en 2010 el $0.013 \%$. La tasa de crecimiento inter-censal entre los valores porcentuales sería de $98.55 \%$. Entonces, 
dicho incremento es demasiado revelador. ${ }^{8}$ En estos detalles es en los que como científicos sociales debemos reflexionar. Es necesario preguntarnos ¿por qué los sujetos en su acto de identificación han puesto en relevancia la identidad budista dentro de la estructura de sus compromisos identitarios? ¿Qué ha pasado o está pasando en la apropiación, reinterpretación o adaptación del budismo entre los mexicanos? ¿Cuáles fueron las modificaciones en la oferta religiosa de los grupos budistas existentes en México, que han llevado a tales resultados estadísticos?

Frigerio nos ofrece dos preguntas más que son esenciales para reflexionar sobre las identidades religiosas subjetivas: ¿quién soy yo? y ¿qué creo yo? (Frigerio, 2007, p. 98-99). En el caso de los censos, es claro que las respuestas emitidas por la población corresponden a la primera pregunta. Hasta ahora, las investigaciones antropológicas y sociológicas se han detenido a pensar en la pregunta "¿qué creo yo?” Los resultados han develado una religiosidad "a la carta", de cómo un católico también puede creer en el karma o en la reencarnación (Fortuny, 1999; De la Torre et al., 2014). No obstante, al considerar el carácter difuso y de minoría del budismo en México, lo que las estadísticas nos estaría diciendo es que en aquellos bricolajes religiosos y sincretismos, las creencias o los elementos simbólicos budistas comienzan a predominar cada vez más en la identidad o identificación religiosa.

Siguiendo a Frigerio (2015), es útil diferenciar tres niveles de identidad: el personal, el social y el colectivo. Para iniciar, podemos cuestionarnos ¿̨uál o cuáles de estas identidades juegan un papel principal en este acto de identificación como budista? Frigerio insiste que para el caso de los católicos argentinos frente a los encuestadores censales lo que reluce es la identidad social y un silenciamiento sobre el lugar del "ser católico" en la identidad personal, así como un encubrimiento sobre su sentido de pertenencia al "nosotros católicos"

8 Es importante mencionar que la cantidad de 2000 se contabilizó sólo a la población de 5 años y más, mientras el dato de 2010 se refiere a la población total; esto llevaría a entender la razón de la alta tasa de crecimiento. Pero aún si comparamos a la población budista de 12 ańos y más de 2010 que son 12,673, el ajuste seguiría siendo considerable.

Debates do NER, Porto Alegre, ano i9, N. 35, P. 237-270, Jan./Jul. 20 i 9 
como identidad colectiva. Claramente, Frigerio (2015) intenta develar algunos errores de interpretación de los datos estadísticos cuando existe en realidad una divergencia entre lo que se dice ser y lo que se cree y práctica. Totalmente de acuerdo y adecuado cuestionarse de esta manera, cuando se habla de una religión "nacional" heredada o tradicional con cierta legitimidad histórica. Esta sería una posible explicación del por qué un sujeto se sigue identificando como católico aun creyendo en la reencarnación, practicando meditación o asistiendo con un chamán por una limpia. Pero ¿qué pasa cuando un individuo se identifica como budista a pesar de seguir asistiendo los domingos a misa o rogándole a Dios para aprobar un examen? El cuestionamiento de Frigerio no resulta ser del todo pertinente al abordar esta religión "atípica” en México, y en la que el sujeto ha decidido distinguirse de la sociedad mayoritaria y no estandarizar su identidad religiosa con la afiliación católica; es otra lógica que falta por dilucidarse. ¿Qué factores conllevan al budista en México para definirse como tal?

Hasta ahora la literatura antropológica sobre el Budismo en Argentina explica bien el por qué aquellos que podríamos, como investigadores, ubicar como budistas a través del trabajo de campo, no se identifican como tales en los censos. Las razones principales es que en el nivel subjetivo, el Budismo no es religión, o el llamarse budistas sería una manera de evitar el apego a los egos, etcétera (Carini, 2011, p. 133-140). Las conclusiones nos dirigirían a entender que la cantidad emitida por los censos puede ser inferior. Pero todavía no nos estaríamos preocupando por ofrecer explicaciones del por qué algunos sí logran colocar su identidad budista para definir al "quién soy yo”. En México, encuentro una reciente tendencia relativamente opuesta del carácter occidental del budismo, la cual invita a negar o no darle importancia a dicha identificación por no considerarla como religión y por caracterizarla como un corpus sin creencias. En síntesis, tenemos pendiente ahondar en la auto y hetero-percepción, y en el auto y hetero-reconocimiento de los llamados budistas en América Latina de manera comparativa. 


\section{¿EN DÓNDE ESTÁN LOS BUDISTAS?}

Las divisiones regionales fueron tomadas del Atlas de la diversidad religiosa en México (De la Torre; Gutiérrez, 2007) con el fin de comparar los resultados estadísticos. De esta manera podremos entender la distribución geográfica de los budistas en México.

Cuadro 3 - Budistas y cristianos en México por regiones

\begin{tabular}{|c|c|c|c|c|c|c|c|c|c|}
\hline \multirow[b]{2}{*}{ Región } & \multirow[b]{2}{*}{ Estado } & \multicolumn{4}{|c|}{2000} & \multicolumn{4}{|c|}{2010} \\
\hline & & Budista & Católico & Protestante & $\begin{array}{c}\text { Para- } \\
\text { protestante }\end{array}$ & Budista & Católico & Protestante & $\begin{array}{c}\text { Para- } \\
\text { protestante }\end{array}$ \\
\hline \multirow{5}{*}{ Noroeste } & Baja California & 4.28 & 2.19 & 3.60 & 3.11 & 10.75 & 2.45 & 4.51 & 3.91 \\
\hline & $\begin{array}{c}\text { Baja } \\
\text { California Sur }\end{array}$ & 0.79 & 0.45 & 0.34 & 0.42 & 0.91 & 0.56 & 0.57 & 0.59 \\
\hline & Sinaloa & 0.49 & 2.61 & 1.48 & 2.59 & 1.35 & 2.50 & 1.68 & 2.51 \\
\hline & Sonora & 0.90 & 2.30 & 2.14 & 2.02 & 2.40 & 2.36 & 2.43 & 2.10 \\
\hline & Suma & 6.45 & 7.55 & 7.57 & 8.14 & 15.42 & 7.86 & 9.18 & 9.11 \\
\hline \multirow{8}{*}{ Noreste } & Coahuila & 1.05 & 2.34 & 3.12 & 2.02 & 1.63 & 2.38 & 3.29 & 2.02 \\
\hline & Chihuahua & 0.99 & 2.97 & 4.21 & 2.96 & 1.24 & 2.80 & 3.85 & 2.75 \\
\hline & Durango & 0.22 & 1.53 & 1.11 & 1.33 & 0.31 & 1.51 & 1.16 & 1.27 \\
\hline & Nuevo León & 3.80 & 4.00 & 4.80 & 3.83 & 3.60 & 4.13 & 4.57 & 3.72 \\
\hline & $\begin{array}{l}\text { San Luis } \\
\text { Potosí }\end{array}$ & 0.51 & 2.48 & 2.12 & 1.14 & 0.67 & 2.47 & 1.77 & 1.14 \\
\hline & Tamaulipas & 2.67 & 2.70 & 4.76 & 3.29 & 0.60 & 2.57 & 4.74 & 3.21 \\
\hline & Zacatecas & 0.26 & 1.52 & 0.52 & 0.65 & 0.23 & 1.50 & 0.50 & 0.61 \\
\hline & Suma & 9.50 & 17.53 & 20.64 & 15.23 & 8.28 & 17.35 & 19.88 & 14.72 \\
\hline
\end{tabular}




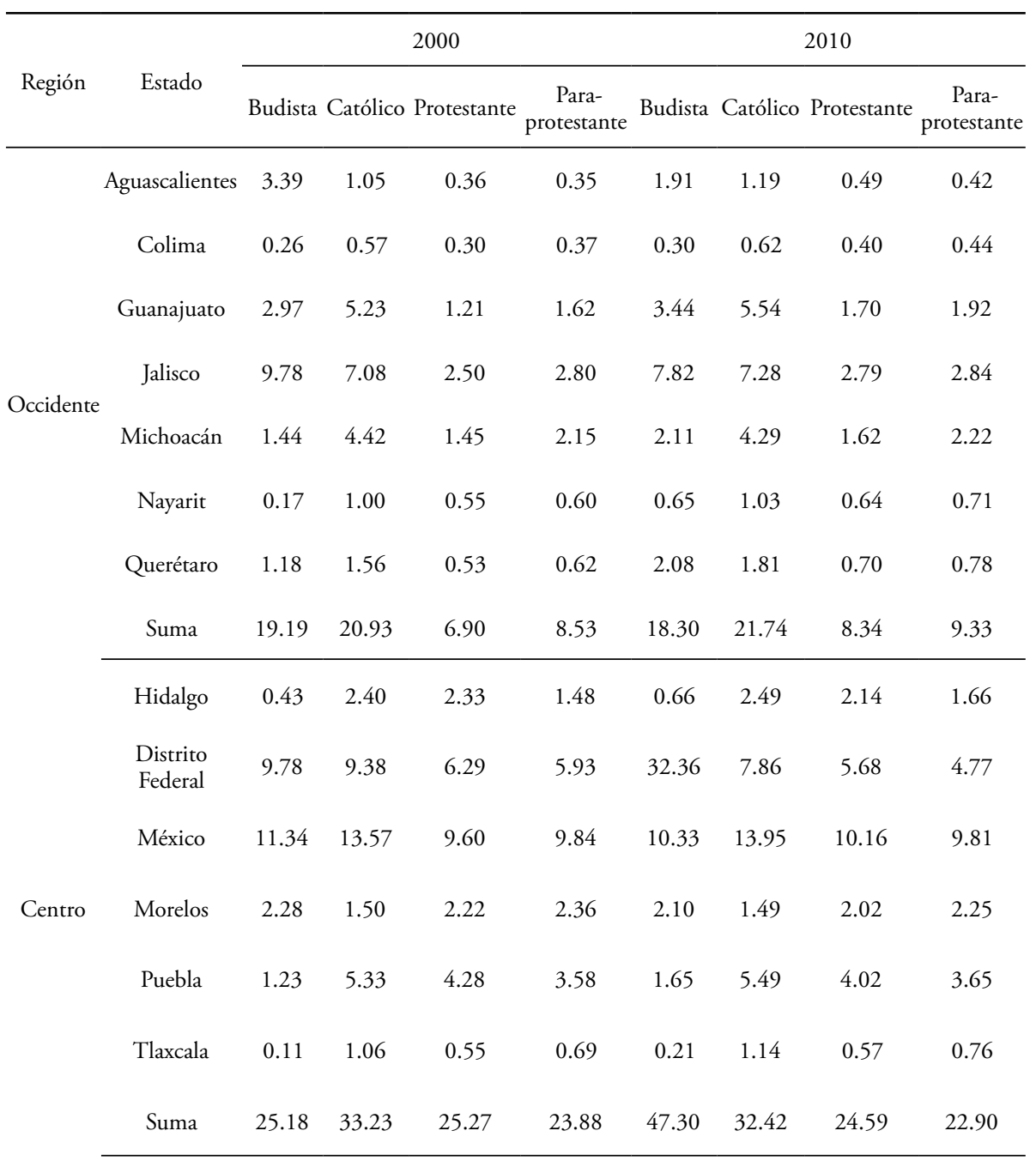




\begin{tabular}{|c|c|c|c|c|c|c|c|c|c|}
\hline \multirow{2}{*}{ Región } & \multirow{2}{*}{ Estado } & \multicolumn{4}{|c|}{2000} & \multicolumn{4}{|c|}{2010} \\
\hline & & Budista & Católico & Protestante & $\begin{array}{c}\text { Para- } \\
\text { protestante }\end{array}$ & Budista & Católico & Protestante & $\begin{array}{l}\text { Para- } \\
\text { protestante }\end{array}$ \\
\hline \multirow{5}{*}{ Sur } & Chiapas & 0.75 & 2.81 & 10.38 & 14.94 & 1.07 & 3.01 & 10.99 & 15.43 \\
\hline & Guerrero & 0.45 & 3.16 & 2.67 & 2.97 & 0.41 & 3.15 & 2.56 & 3.07 \\
\hline & Oaxaca & 0.65 & 3.43 & 5.31 & 3.98 & 0.76 & 3.30 & 4.76 & 4.04 \\
\hline & Veracruz & 5.31 & 6.80 & 9.60 & 11.48 & 2.92 & 6.47 & 8.38 & 10.09 \\
\hline & Suma & 7.16 & 16.20 & 27.96 & 33.37 & 5.16 & 15.93 & 26.69 & 32.63 \\
\hline \multirow{5}{*}{ Sureste } & Campeche & 0.19 & 0.58 & 1.81 & 1.62 & 0.08 & 0.56 & 1.62 & 1.47 \\
\hline & $\begin{array}{l}\text { Quintana } \\
\text { Roo }\end{array}$ & 2.23 & 0.74 & 1.91 & 1.98 & 2.77 & 0.90 & 2.28 & 2.41 \\
\hline & Tabasco & 0.17 & 1.57 & 5.14 & 4.74 & 0.31 & 1.55 & 4.90 & 4.95 \\
\hline & Yucatán & 3.50 & 1.66 & 2.79 & 2.52 & 2.38 & 1.67 & 2.52 & 2.47 \\
\hline & Suma & 6.08 & 4.56 & 11.66 & 10.86 & 5.54 & 4.69 & 11.32 & 11.30 \\
\hline \multicolumn{2}{|c|}{ Total por religión } & 100 & 100 & 100 & 100 & 100 & 100 & 100 & 100 \\
\hline
\end{tabular}

Fuente: Elaboración propia con base en los microdatos de 2000 y tabulados de 2010 del INEGI.Nota: La categoría de protestantes incluye a los protestantes históricos (presbiterianos, bautistas, metodistas, etc.) y pentecostales. En el rubro para-protestante se cuenta a los Adventistas del Séptimo Día, Testigos de Jehová y Mormones.

A primera vista, la región norte ya no posee la mayoría de la población budista; la cual recordamos, se debió a las comunidades de inmigrantes asiáticos asentados en esta zona del país. En 2000, Centro y Occidente son las regiones con mayor cantidad de budistas, al igual que el porcentaje de católicos. Los protestantes predominan en el Sur y en segundo lugar en el Centro y del mismo modo los para-protestantes. En 2010, surge la región Noroeste como otra de las regiones con alto porcentaje de budistas 
junto al Centro y Occidente. Distrito Federal (actual CDMX) creció un $22.58 \%$. Mientras Baja California pasó de $4.28 \%$ a $10.75 \%$, siendo el factor primordial del aumento porcentual de Noroeste. En el cuadro 2 vemos que Sinaloa, Sonora y Coahuila están entre los estados con una alta tasa anual de crecimiento, en tanto que el Distrito Federal sólo 13.50\%. Por tanto, los budistas aún permanecen centralizados en la capital, pero con tendencias de desplazamiento al norte.

Gráfica 2 - Budistas y cristianos por región, 2000

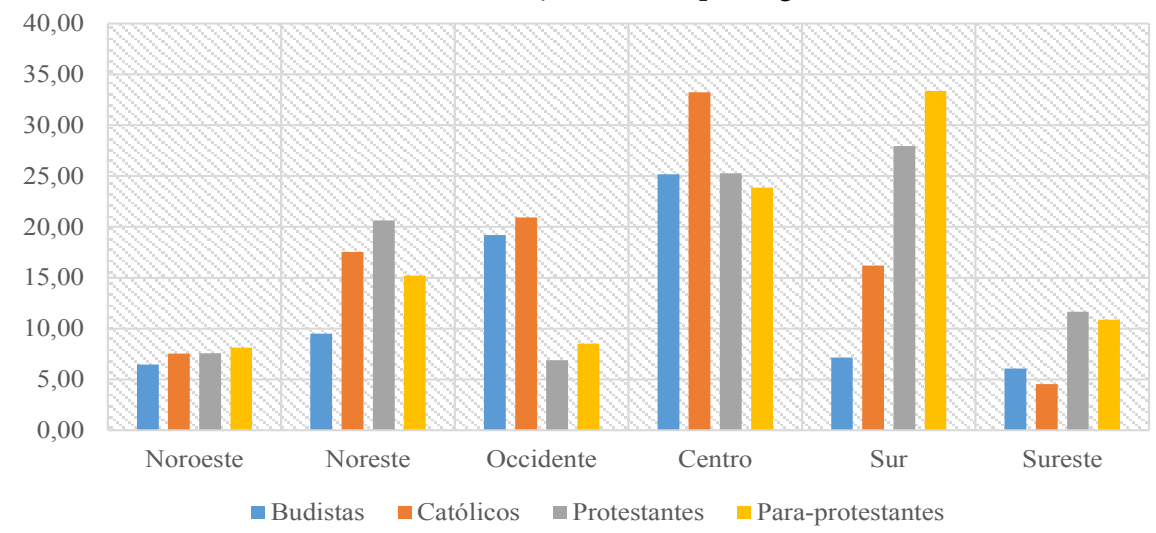

Fuente: Elaboración propia con base en los tabulados de 2010, INEGI 
Gráfica 3 - Budistas y cristianos por región, 2010

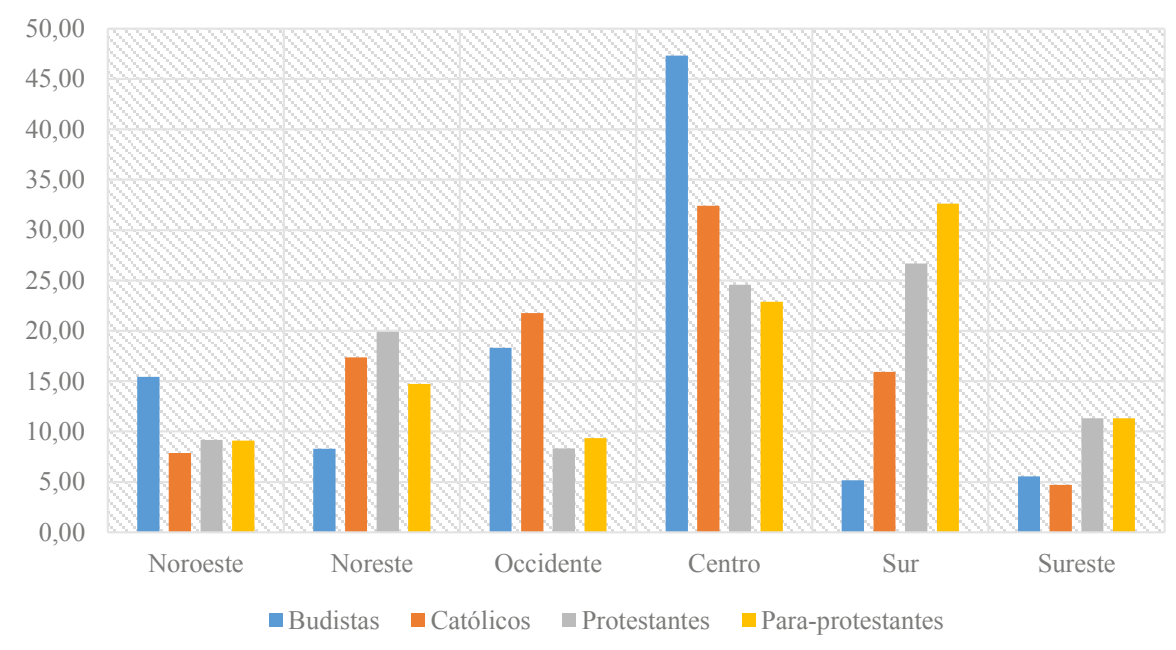

Fuente: Elaboración propia con base en el censo 2010, INEGI

Tanto en 2000 y 2010 se aprecia la conglomeración de los budistas en el Centro y Occidente con 47.3\% y 18.3\%, respectivamente. Así también Jalisco, Distrito Federal y Estado de México son los centros de flujo de budistas, muchos inmigran a estos estados y así mismo muchos emigran al resto de las entidades.

Esta distribución geográfica es relevante cuando las regiones de Centro y Occidente son consideradas como bastiones del catolicismo; tal como podemos ver en la gráfica 2 y 3 , son en estas dos regiones donde la cantidad de católicos se superponen a la de los protestantes y para-protestantes. De la misma forma, son vistas como regiones con un cambio religioso lento o moderado debido a que el crecimiento de los protestantes y para-protestantes no presenta variaciones en ambos censos y el decrecimiento de los católicos resulta mínimo (De la Torre; Gutiérrez, 2007). Por tanto, existe una relación positiva entre el alto porcentaje de budistas y la presencia significativa de católicos. 
Este resultado preliminar nos invita a reflexionar en torno a cómo medimos los niveles o grados de cambio religioso. La manera habitual ha sido evidenciando el declive del catolicismo y el avance de grupos cristianos no-católicos. Tal vez sea importante añadir a los grupos no-cristianos para escapar de la visión dicotómica y dual basada en el catolicismo. Así mismo, demuestra lo endeble de la tesis expresada por Morales Ramírez, quien dice que uno de los factores de "la conquista del BuddhaDharma en México" es el descenso del catolicismo (Ramírez, 2014, p. 286).

La conexión descubierta desde las estadísticas permite aludir cinco cuestiones hipotéticas: 1) la mayoría de los budistas conversos poseen antecedentes católicos; 2) el crecimiento de los grupos evangélicos-protestantes es neutralizado por la oferta budista; 3) El grado de subjetivación y poco compromiso en el catolicismo actual, y la flexibilidad y no exclusivismo del budismo permite entender por qué los individuos pueden identificarse con menos diferencia como budistas o católicos en los censos; 4) El carácter sincrético del catolicismo en México permite la convivencia con grupos no-cristianos como el budista; a diferencia de los grupos protestantes que exigen la exclusividad y no mezcla con otras creencias; y 5) el budismo tiene una mayor aceptación en ambientes católicos debido a ciertas alineaciones de los marcos interpretativos con la práctica religiosa católica, que pueden ser observados en el uso de rosarios y de la realización de oraciones repetitivas. ${ }^{9}$

Para el caso de la distribución por tipo o tamaño de localidad, usé la categorización propuesta por Luis Unikel (1976) quien clasifica las localidades en cuatro: 1) rural (menos de 5 mil habitantes); 2) mixta rural (más de 5 mil y menos de 10 mil habitantes); 3) mixta urbana (más de 10 mil y

9 Esta afirmación se basa en el concepto de frame alignment (alineación de marcos interpretativos), en el que entendemos que a nivel de la práctica religiosa los "intereses, valores y creencias de los individuos se vean como congruentes y complementarios" (Snow et al., 1986, p. 464). 
menos de 15 mil habitantes); y 4) urbana (mayor de 15 mil habitantes). ${ }^{10} \mathrm{El}$ $93.8 \%$ de la población total budista de 2010 reside en poblaciones mayores de 15 mil habitantes, por lo que asumimos que el Budismo en México es de carácter urbano. Aunque, por otro lado, llama la atención que el 3.9\% se ubique en la zona rural y $2.3 \%$ en ambas mixtas, considerando que hay mayor cantidad de budistas en la mixta rural que en la mixta urbana.

Estos datos que parecen fuera de lo típico o no esperado, nos indica que hay un número considerable de budistas localizados en zonas rurales, de lo cual, se deduce que sean monasterios o templos de retiro. Una gran parte de las organizaciones budistas en México destinan sus recursos para la instalación de dichos monasterios; esto no ha significado ausencia de conflictos en su llegada a estas zonas, como el caso de la asociación Buddhismo Theravada México con su monasterio Dhamma Vihara ubicado en Jilotepec, Veracruz.

[El] monasterio se encuentra en un lugar rural, donde sí tuvimos problemas para el paso. Al principio fue difícil porque algunos vecinos veían con buenos ojos que íbamos y otros quizá no, y de alguna manera llegaron a impedir el paso, y tuvo que recurrirse a la ley para establecerse que abrieran un camino de paso para todos... (María Morales, entrevista oral, 03/10/2014). ${ }^{11}$

El establecimiento de los sitios de meditación y retiros no se reducen sólo a la ciudad; sino también a las localidades que resultan ser idóneas para dichas actividades, en las que podemos inferir que cuentan con un cuerpo de maestros y guías residiendo en estos lugares. En cierto modo, nos habla del perfil del budismo en México.

${ }^{10}$ Esta clasificación estuvo basada no sólo en la cantidad poblacional, sino que incluyó las variables de población económicamente activa del sector secundario y terciario, la población alfabeta, con estudios primarios finalizados y asalariada. Las categorías mixtas indican la fase de transición del proceso y desarrollo urbano.

${ }^{11}$ Entrevista realizada a la presidenta de la asociación María Alina Morales Troncoso por el autor. 


\section{¿BUDISTAS ÉTNICOS O CONVERSOS?}

Cuando hablamos de una religión ajena, lo primero que le inquieta a las ciencias sociales es si su membresía ha dejado de ser extranjera o no. El caso del protestantismo en México resulta esclarecedor al relacionarlo en el siglo XIX como opositor de la patria mexicana o como medio de penetración imperialista norteamericana (Stoll, 1985; Bastian, 1990). Por eso es necesaria la distinción entre Budismo étnico y Budismo de conversos, así como de la noción de Congregaciones paralelas (Numrich, 1996). Aunque algunos han enunciado que las diferenciaciones del budismo al exterior de Asia deben ser mejor matizadas y desde otros ángulos (Baumann, 2001).

Cuadro 4 - Budistas en México por lugar de nacimiento (\%)

\begin{tabular}{ccc}
\hline Lugar & 2000 & 2010 \\
\hline En el país & 60.49 & 67.14 \\
En otro país & 39.13 & 32.56 \\
\hline Total nacional & 100 & 100 \\
\hline Asia & 83.89 & 82.55 \\
América & 12.62 & 14.18 \\
Europa & 3.3 & 3.08 \\
\hline Total otro país & 100 & 100 \\
\hline China & 26.32 & 57.45 \\
Japón & 62.34 & 26.75 \\
Corea & 6.78 & 7.91 \\
\hline Total Asia & 100 & 100
\end{tabular}

Fuente: Elaboración propia con base en los microdatos del censo 2000 y tabulados de 2010 del INEGI

Los datos censales nos dicen que el budismo en México no es predominantemente extranjero, más de la mitad de los que se identificaron como budistas nacieron y se socializaron en tierras mexicanas. Aunque silencia la capacidad económica para viajar fuera de México en donde muchos tienen contacto con otras formas de pensar y creer. Sin embargo, el trabajo de 
campo y las entrevistas revelan que el viaje hacia países tradicionalmente budistas es consecuencia de su previa conversión, simpatía o contacto con el budismo en México.

Por un lado, encontramos que los budistas no-extranjeros tienen un papel importante en las entidades con mayor porcentaje de adscripción al budismo. Si indagamos en los estados con mayor porcentaje de budistas, encontramos que en Distrito Federal (actual CDMX) 3,306 nacieron en México y 1,043 en Asia. En Jalisco 831 nacieron en este país y 180 proceden de Asia. En el caso de Baja California, el estado que experimentó uno de los crecimientos más llamativos encontramos que 470 son nacidos en tierra mexicana y 969 en Asia. Por lo cual merece una atención primordial, ya que en 2000, los budistas nacidos en Asia sólo ascendían a 82 en contraste de los 113 locales.

Por otro lado debemos tener cuidado con el filtro de 'lugar de nacimiento', ya que se pueden incluir a las segundas o terceras generaciones de inmigrantes asiáticos. Claramente, este sector poblacional sería muy reducida y otorgarle un porcentaje alto sería aventurado. Como parte del proceso de aculturación las generaciones ulteriores de familias asiáticas han optado por el catolicismo. Como vimos en el apartado anterior, la mayor parte de la población budista se encontraba en las regiones más católicas del país.

Existen varios casos de japoneses residentes en México que evidencian lo dicho, como el de la familia Doode que:

Aun a la distancia, Mitsuo y Sala practicaban el budismo shintoísta [sic], aunque eran amplios conocedores de lo mexicano. Sin embargo, como otras parejas japonesas, optaron por criar a sus hijos como católicos y no como budistas; consideraban una ventaja el ser católicos en un mundo laboral y social dominado por el catolicismo (Cañez de la Fuente et. al., 2010, p. 151). ${ }^{12}$

${ }^{12}$ CAÑEZ DE LA FUENTE et al. Ser japonés en México. Relatos de un inmigrante. Culturales, p. 151. 
Las generaciones nikkei en México han reformulado su identidad étnica e inmigrante hacia una mestizo-filia, en la que se supere el ser japonés y el ser mexicano al mismo tiempo; es decir, se ha creado una tercera identidad que des-marginaliza su condición liminar por no ser un japonés puro, debido al nacimiento fuera de Japón y tampoco ser un mexicano puro a causa de su frontera corporal (Melgar, 2011, p. 129-131). Por tanto, por un lado, la adopción del catolicismo viene a dotarle de mexicanidad que supera lo japonés en la búsqueda de trabajo; y por el otro, frente al boom económico transnacional nipón arribado a México le dota al nikkei de una mayor eficiencia administrativa frente al mexicano sin ascendencia japonesa (Melgar, 2011, p. 131).

Esta tendencia del declive del Budismo Étnico parece ser generalizada. En Rio Grande do Sul de Brasil, muchos japoneses adoptan los ritos católicos para lograr integrarse a la sociedad. El hecho de bautizar a los hijos japoneses en iglesias católicas le permite a la familia asiática hacerse de padrinos que los ayuden a subsistir. Esto dificulta a las generaciones ulteriores, ya que se encuentran en una condición ambigua para identificarse religiosamente. En estos casos se puede hablar de convivencia y no de sincretismo (Gaudioso; Ramos, 2015). Según Usarski (2008), esto se debe principalmente a las deficiencias infra-estructurales de las asociaciones budistas y al mantenimiento de la lengua originaria en la religión frente a generaciones postreras con un progresivo abandono del mismo idioma (Usarski, 2008, p. 141-147). Por tanto, desde esta información censal podemos afirmar que el budismo en México no es étnico, pero tampoco se puede asegurar que sea totalmente de conversos.

\section{BUDISMO Y BUDISTAS. DE DÓNDE VIENE Y A DÓNDE VA}

Por otra parte, la mayoría de los budistas nacidos en otro país proceden del continente asiático, pero con un descenso del 1\%. Mientras tanto, los provenientes del continente americano crecieron cerca del $2 \%$, en la que 
adquieren importancia los sudamericanos. Esto nos apunta que los centros de difusión del budismo están en proceso de descentralizarse de Asia; es decir, la globalización de esta religión no responde únicamente al proceso unidireccional de Oriente a Occidente (Carini, 2009). En el caso de México, la asociación Buddhismo Theravada México ofrece cursos en línea sobre Budismo, a través del Instituto de Estudios Buddhistas Hispano (IEBH), a varias personas residentes fuera del país, como España, Argentina, Chile, Uruguay y Estados Unidos. El IEBH se encuentra a cargo del venerable U Nandisena, nacido en Argentina con nacionalidad norteamericana. Este es uno de los ejemplos paradigmáticos de la descentralización en el proceso de globalización del Budismo, en el que México funge como un difusor del Budismo por medio de cursos vía internet y con un monje abad originario de Sudamérica.

Imagen 1 - Equipo del Instituto de Estudios Buddhistas Hispano

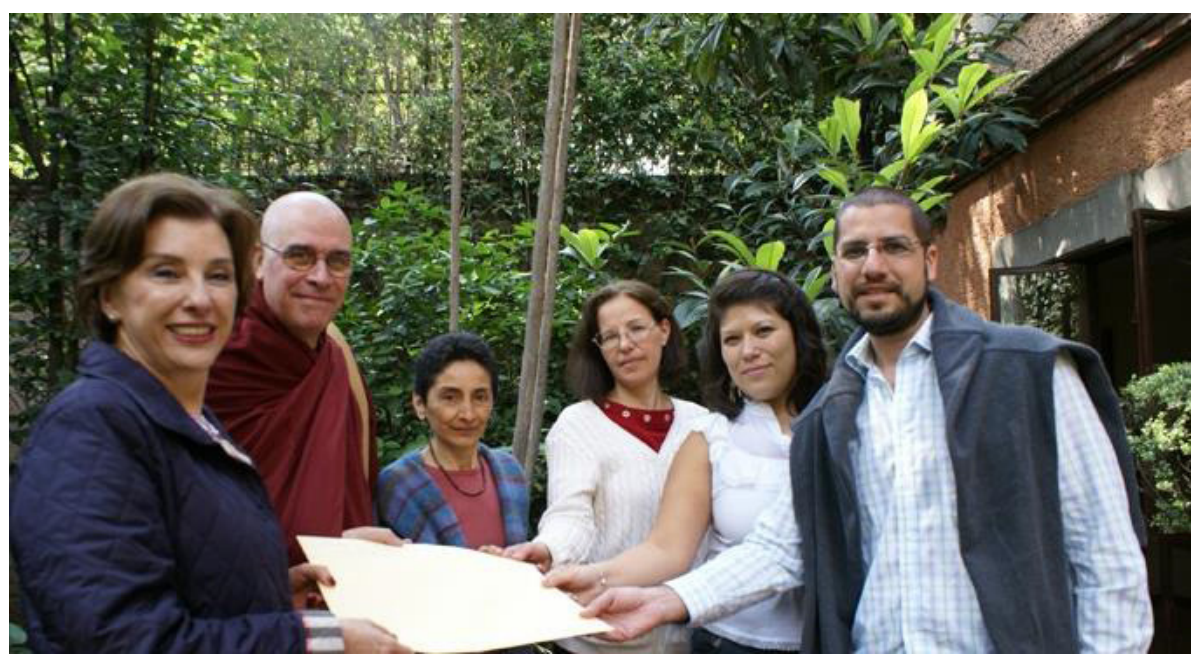

Fuente: http://iebh.org/node/43 


\section{LA PIRÁMIDE BUDISTA}

La pirámide poblacional nos permite indagar sobre la distribución por sexo y edad; esto es, conocer la estructura demográfica de los budistas. Como puede observarse en las pirámides, la población adulta-joven predomina en la estructura demográfica, esto es de 25 a 39 años. En ambos censos encontramos esta tendencia con ligeros matices. En este sentido, puede afirmarse que el perfil de la pirámide budista es progresiva y desde la visión demográfica clásica se diría que tiene perspectivas de crecimiento.

Dadas estas características, es importante preguntarse si el Budismo se encuentra más atractivo entre los adultos-jóvenes o si se trata de un crecimiento biológico; es decir, hijos de padres budistas (no conversos). Aunque lo que se intuye al observar las bases de ambas pirámides (sección niños-adolescentes, jóvenes y adultos-jóvenes ${ }^{13}$ ) es un desplazamiento de las "salientes" de los jóvenes a la de adultos-jóvenes; en caso de seguir esta tendencia lo que se proyecta es un posible envejecimiento de la población budista.

Responder estas interrogantes resulta revelador ya que indicaría el perfil de las organizaciones budistas no-inmigrantes; es decir, los modos de transmisión religiosa, canales de difusión y motivos de conversión. El caso de la Soka Gakkai de Yucatán apunta a la tendencia del envejecimiento de su membresía, para el 2011 el $64.34 \%$ pertenecían al sector etario adulto y de tercera edad; mientras sólo el $26.95 \%$ estaban inscritos a los grupos juveniles (May, 2012, p. 70). No obstante me parece importante no quedarnos con esta última consideración, que es muy preliminar y no generalizable. Por tanto, la invitación es para indagar en las condiciones socio-históricas de finales de los cincuenta y segunda mitad de los años sesenta, los cuales constituyen el periodo de nacimiento del mayor sector etario de la población budista en México.

${ }^{13}$ La división de las edades es la siguiente: niños-adolescentes, 0-14 años; jóvenes, 15-24 años; adultos-jóvenes, 25-39 años; adultos: 40-59 años y tercera edad, 60-85 años y más.

Debates do NER, Porto Alegre, Ano i 9, N. 35, P. 237-270, Jan./Jul. 20 i 9 
Imagen 2 - Pirámide poblacional budista, 2000

Piramide 1

Población budista, 2000

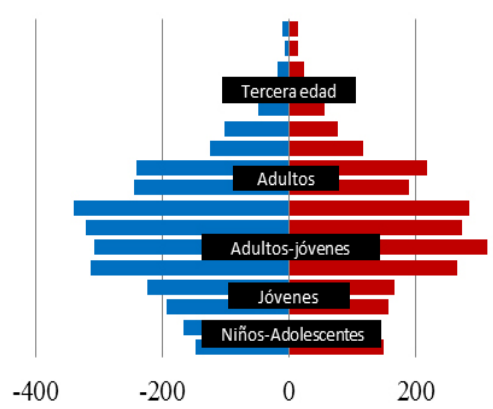

Imagen 3 - Pirámide poblacional budista, 2010

Piramide 2

Población budista, 2010

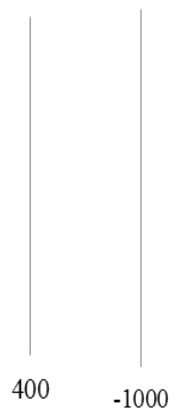

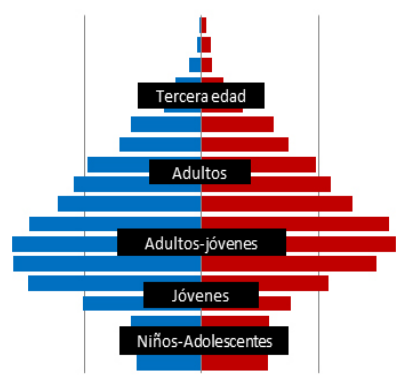

$-500$

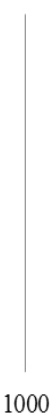

Fuente: Elaboración propia con base en los microdatos de 2000 y tabulados de 2010, INEGI

Una observación muy particular que reluce al comparar la pirámide budista con la católica, protestante/ pentecostal/evangélica, adventista, mormona y la de los Testigos de Jehová del año 2010, es que la parte céntrica "saliente" de la budista pertenece a la sección "entrante" de las otras mencionadas; es decir, la población entre 25 y 39 años es minoritaria en los demás grupos religiosos, y mayoritario en el budismo (INEGI, 2011, p. 4-8). ¿Podría decirse que la mayoría de los adultos-jóvenes budistas corresponde a la ausente de la población católica, protestante y para-protestante? ¿Sería una posible respuesta a la pregunta de dónde está la población que le hace falta a estas otras?

Respecto al variable sexo, la relación hombres-mujeres cambia durante el decenio. En 2000 los hombres predominaban en el sector "saliente" de la pirámide, mientras en los "salientes" de 2010 las mujeres poseían la cantidad superior. Este detalle se corrobora desde la observación cualitativa, pues se encuentra una participación activa de las mujeres en las posiciones de liderazgo de las organizaciones budistas, tanto en el nivel administrativo y 
religioso; muchas son presidentes de las asociaciones, son monjas-maestras o encargadas de los grupos de meditación, etcétera. Ahora la interrogante es ¿cuál es el motivo de la tendencia del incremento de la población femenina entre los budistas? Aunque esta característica es muy general en casi todos los grupos religiosos; sin embargo, para el caso budista, la situación conyugal nos ofrece algunas pistas.

\section{ESTATUS CIVIL}

La tendencia entre la población que se adscribe al budismo es mayormente de estatus civil independiente y autónomo, esto lo evidencia el cambio ocurrido en los números durante el decenio 2000-2010. En este último año, la cantidad de personas solteras, divorciadas, separadas y viudas suman 6,514, mientras los casados y en unión libre 6,108 personas; en los casados, 2,500 se matrimoniaron sólo por el civil del total de 4,729. Por una parte, este dato es obvio si recordamos que una fracción representativa de la población es joven y adulta joven, quienes no se encuentran en una edad promedio para casarse. Por otra, nos indica que el budismo se ha concentrado en una población que se localiza en su pleno desarrollo laboral o en la etapa de independización familiar.

Cuadro 5 - Situación conyugal de los budistas en México 2000

\begin{tabular}{cccc}
\hline Estado Civil & Hombre & Mujer & Total \\
\hline Soltero(a) & 987 & 686 & 1,673 \\
\hline Casado(a) & 1,249 & 1,036 & 2,285 \\
sólo por el civil & 546 & 477 & 1,023 \\
sólo religiosamente & 37 & 26 & 63 \\
civil y religiosamente & 666 & 533 & 1,199 \\
\hline Unión libre & 206 & 176 & 382 \\
\hline
\end{tabular}




\begin{tabular}{cccc}
\hline $\begin{array}{c}\text { Alguna vez unido } \\
\text { (separado, divorciado } \\
\text { y viudo) }\end{array}$ & 170 & 398 & 568 \\
\hline No especificado & 16 & 9 & 25 \\
\hline Total & 2,628 & 2,305 & 4,933 \\
\hline
\end{tabular}

Fuente: Elaboración propia con base en los microdatos del censo de 2000, INEGI Nota: La población contabilizada es de 12 años y más.

Esta tendencia de la correspondencia entre el estatus civil independiente y la adscripción al budismo tiene que ver con la individualización en la religiosidad, así como la aceptación por parte de esta religión de la condición poco convencional de la familia, donde sólo existe una figura de las dos existente: paterna y materna. Por ejemplo, la moral católica o evangélica no aceptaría una relación en unión libre a diferencia de cualquier asociación budista; por un lado, porque otorgan un alto grado de libertad en la toma de decisión de las personas y por el otro, a que esta actitud tolerante es necesaria para la consecución de una mayor aceptación entre los sujetos marginados moralmente. De la misma manera sucede con las mujeres divorciadas y separadas.

Cuadro 6 - Situación conyugal de los budistas en México 2010

\begin{tabular}{cccc}
\hline Estado Civil & Hombre & Mujer & Total \\
\hline Soltero(a) & 2,779 & 2,248 & 5,027 \\
\hline Casado(a) & 2,431 & 2,298 & 4,729 \\
sólo por el civil & 1,243 & 1,257 & 2,500 \\
sólo religiosamente & 199 & 166 & 365 \\
civil y religiosamente & 989 & 875 & 1,864 \\
\hline Unión libre & 726 & 653 & 1,379 \\
\hline Separado(a) & 137 & 242 & 379 \\
\hline
\end{tabular}




\begin{tabular}{cccc}
\hline Divorciado(a) & 252 & 483 & 735 \\
\hline Viudo(a) & 80 & 293 & 373 \\
\hline No especificado & 29 & 22 & 51 \\
\hline Total & 6,434 & 6,239 & 12,673 \\
\hline
\end{tabular}

Fuente: elaboración propia con base en los tabulados del censo 2010, INEGI. Nota: la población contabilizada es de 12 años y más.

Regresando al asunto del predominio de la población femenina, encontramos un punto sugerente. Si observamos los datos a detalle nos percataremos que en ambos censos, el rubro donde las mujeres adquieren superioridad es en el estatus de separada, divorciada y viuda. Entre las mujeres miembros de la Soka Gakkai se confirma este perfil, una porción significativa había pasado directa o indirectamente por una experiencia de divorcio o separación.

El siguiente testimonio proviene de una mujer de 60 años miembro de la Soka Gakkai, este es uno de los mejores ejemplos de lo antes dicho:

[...] fui a pedirle apoyo al Padre [sacerdote católico], me excomulgaron de la Iglesia porque me había divorciado; el Padre que me casó dejó los hábitos, o sea fueron muchas circunstancias. ¿¿Cómo es que yo le estoy pidiendo a Dios... y me van a excomulgar? o sea, yo era muy apegada, sabía todo lo que era la religión [católica]. Entonces, mi vida estaba en depresión, y si nadie está haciendo nada por mí era evidente que yo tenía que hacerlo. Entonces, ahí fue donde fui tomando conciencia (Mujer, 03/03/2011). ${ }^{14}$

El budismo coadyuva a empoderar a las mujeres que se han convertido en jefas de familia, en las que cumplir los deberes de la casa se suma a la responsabilidad de llevar ingresos al hogar; o en los casos de hijos de padres divorciados, les sirve para adquirir el rol de autoridad en ausencia de la misma. Por tanto, la condición de abandono es uno de los principales

${ }^{14}$ Entrevista realizada por el autor a una miembro de la Soka Gakkai de Mérida, Yucatán. 
motivos para ver en el budismo un buen aliciente y garante para superar su condición civil, y hacer de ella una virtud y fortaleza.

\section{ULTIMAS REFLEXIONES}

La comunidad académica mexicana dedicada al estudio del fenómeno religioso quedan a deber a las religiones orientales. El escaso conocimiento al respecto es preocupante, ya que esta desatención habla mucho del peso de las variables o rasgos en las justificaciones de nuestras pesquisas científicas: lo cuantitativo como condición para indagar lo cualitativo. La población budista en México ni siquiera rebasa la cantidad de 20,000 personas, pero su tasa de crecimiento es sorprendente e innegable. Este número muy pequeño a nivel nacional no nos permite ver a este conjunto de individuos con intereses, valores y actitudes particulares en relación a la economía, política y desarrollo humano.

En este sentido, la importancia de atender a sectores minoritarios con tendencias grandes como la budista sería por un lado, útil para reflexionar sobre la dirección y sentido de los cambios sociales que acaecen en México en relación a los valores y las actitudes, al considerar que el budismo también trae consigo una ética moral y económica. Por otro, conocer los cambios y continuidades que impulsa la población budista; es decir, su impacto social como agentes activos en la sociedad.

Muchas tareas quedan pendientes al respecto. La religiosidad budista asiática aún no ha sido explorada a profundidad, aunque tenemos un considerable corpus de conocimiento en relación a la adaptación social de los migrantes asiáticos en México. Aquí sólo pude realizar algunos apuntes que nos indican una correlación entre la distribución budista y la concentración de inmigrantes asiáticos a finales del siglo XIX y principios del XX.

Todavía falta discutir más sobre la identidad budista en México, ¿cómo la cultura religiosa mexicana interviene en este proceso? Algo que sí se observó es que cada vez más sujetos tienden a identificarse como budistas, quienes 
son invisibilizados por ser percibidos desde la visión teórica dominante del menú religioso o del carácter no-religioso del mismo. Este abordaje resulta preocupante al considerar el contexto católico en el que nos encontramos, porque se sigue definiendo a los otros como no-religión en contraste con los que sí son religión como la católica; puesto que se toma de base referencial a la estructura jerárquica y piramidal del catolicismo. No obstante, podría objetarse esta idea a través de la perspectiva emic, en la que el propio sujeto dice no pertenecer a una religión, sino seguir una filosofía. Pero se olvida que la misma auto-definición es también una construcción social y en el caso del budismo, una occidental.

La convivencia particular entre el budismo y el catolicismo no se había propuesto como hipótesis, ya que partimos de la premisa que todo cambio religioso o inserción de nuevos grupos religiosos es reflejo de la pérdida del monopolio católico. Apenas se comienza a cuestionar estas nociones teóricas que han llegado a ser paradigmas; sin embargo, sabemos que todo paradigma tiene que revolucionarse. Las estadísticas censales nos demuestran que grupos no-cristianos, como la budista, encuentran un espacio más abierto en los ambientes católicos. Por tanto, nos invita a pensar en los parámetros con los que medimos el cambio religioso, para escapar del dualismo: católicos-protestantes.

La estructura demográfica de la población budista nos presenta indicios respecto en cuál sector poblacional es en la que el budismo tiene un papel importante en su identificación religiosa. También nos permite establecer conexiones entre qué condiciones sociales y etapas de la vida del sujeto, el budismo cumple la función social y espiritual. Sin embargo, nos oculta la película completa de este proceso de implantación, puesto que falta indagar en los modos de transmisión y difusión religiosa que han resultado efectivas para dicho crecimiento de la población budista o para la concentración en un determinado sector etario.

Para finalizar, algunas tendencias que también merecen atención es la feminización de la fracción poblacional budista. Aquí ofrecimos una posible explicación que ayuda a distinguir de las causas encontradas en otros credos 
religiosos. No obstante, creo que es evidente que la condición civil y etaria tiene una relación con el sentido individualizante del budismo y al mismo tiempo con el sentido comunitario.

Una de las principales característica es que el budismo en México ya no es una religión de extranjeros e inmigrantes. El budismo llegó desde más de un siglo, pero ahora se encuentra en la fase embrionaria en que se visibiliza social, pública e identitariamente y merece nuestra atención.

\section{REFERENCIAS}

BASTIAN, Jean-Pierre. Historia del protestantismo en América Latina. México: CUPSA, 1990.

BAUMANN, Martin. Global Buddhism: Developmental Periods, Regional Histories, and a New Analytical Perspective. Journal of Global Buddhism, Frohburgstrasse, v. 2, p. 1-43, 2001

BERGES, Juana; PLATERO, Silvio; RAMÍREZ, Jorge; TRIANA, Pedro. Los llamados Nuevos Movimientos Religiosos en el Gran Caribe. La Habana: CEA, 2006.

CAÑEZ DE LA FUENTE, Gloria; DOODE, Olga; HERNÁNDEZ, Gabriela. Ser japonés en México. Relatos de un inmigrante. Culturales, Mexicali, v. 6, n. 11, p. 129-158, 2010.

CARINI, Catón. Las nuevas tierras del Buda: globalización, medios de comunicación y descentralización en una minoría religiosa de la Argentina. Debates do Ner, Porto Alegre, v. 2, n. 16, p. 49-70, 2009.

CARINI, Catón. Etnografía del Budismo Zen argentino: rituales, cosmovisión e identidad. Tesis (Doctorado en Antropología Social) - UNLP, La Plata, 2011. DANYLUK, Angie. To be or not to be: Buddhist selves in Toronto. Contemporary Buddhism, Londres, v. 4, n. 2, p. 127-141, 2003. 
DE LA TORRE, Renée; GUTIÉRREZ, Cristina (coords.). Atlas de la diversidad religiosa en México. México: Coljal: Colef: Ciesas: Colmich: Uqroo: Segob, 2007

DE LA TORRE, Renée; GUTIÉRREZ, Cristina; PATIÑO, María; SILVA, Yasodhara; SUÁREZ, Hugo; ZALPA, Genaro. Creer y practicar en México: comparación de tres encuestas sobre religiosidad. México: UAA: CIESAS: Coljal, 2014.

DE LA TORRE, Renée; GUTIÉRREZ, Cristina. Genealogias de la Nueva Era en México. Rever: São Paulo, ano 16, n. 2, p. 55-91, 2016

DIEZ DE VELASCO, Francisco. Budismo en España: historia, visibilización e implantación. Madrid: Akal, 2018.

FORTUNY, Patricia (coord.). Creyentes y creencias en Guadalajara. México: CIESAS: Conaculta: INAH: SEP: Conacyt, 1999.

FORTUNY, Patricia. Diversidad y especificidad de los protestantes. Alteridades, CDMX, v. 11, n. 22, p. 75-92, 2001.

FRIGERIO, Alejandro. Repensando el monopolio religioso del catolicismo en Argentina. In: CAROZZI, María; CERIANI, César (eds.). Ciencias sociales y religión en América Latina: perspectivas en debate. Buenos Aires: Biblos: ACSRM, 2007. p. 87-118.

FRIGERIO, Alejandro. Nuestra elusiva diversidad religiosa: cuestionando categorías y presupuestos teóricos. Corpus, Mendoza, v. 3, n. 2, Disponível em: http://corpusarchivos.revues.org/313. Publicado em: 9 dic. 2013. Acesso em: 4 mayo 2015.

FUJIWARA, Eiko. El Zen y su desarrollo en México. México: CEAPAC: Plaza y Valdés, 1998

GAUDIOSO, Tomoko; RAMOS, André. Entre o Butsudan e a missa: práticas religiosas de imigrantes japoneses no Rio Grande do Sul, Brasil. Amérique Latine Histoire et Mémoire. [En línea], Paris, n. 20. Disponível 
em: http://alhim.revues.org/3667. Publicado el: 08 abr. 2011. Acesso em: 2 mayo 2015.

GUTIÉRREZ, Cristina. Nuevos movimientos religiosos: el New Age en Guadalajara. Relaciones. Estudios de historia y sociedad, Michoacán, v. 17, n. 65-66, p. 84-114, 1996.

HERNÁNDEZ, Miguel. Aprendiendo a deconstruir el sufrimiento: los meditadores budistas en México. In: SUÁREZ, Hugo; ZUBILLAGA, Verónica; BAJOIT, Guy (coord.). El nuevo malestar en la cultura. México: IIS/ UNAM, 2012. p. 217-239.

HINCAPIÉ, Luz. Rutas del pacífico: inmigrantes asiáticos a América Latina. In: Anais. XIII Congreso Internacional de la Asociación Latinoamericana de Estudios de Asia y África, 2001, Bogotá, Colombia. Bogotá: ALADAA, 2001, p. 2, 8, 11.

INEGI. Panorama de las religiones en México 2010. México: INEGI, 2011 INOUE, Daisuke. Soka Gakkai en México. Estudio sobre un Nuevo Movimiento Religioso desarrollado en un contexto cultural ajeno y el proceso de conversión. Tesis (Doctorado en Antropología Social) UNAM, CDMX, 2003.

MAY MAY, Ezer R. Hacía la revolución humana. Conversión y organización religiosa en la Soka Gakkai de Mérida, Yucatán. Tesis (Licenciatura en Antropología Social) UADY, Mérida, 2012.

MAY MAY, Ezer. Institucionalización de un Nuevo Movimiento Religioso japonés en Yucatán. Historia y organización de la Soka Gakkai. Península, Mérida, v. 10, n. 1, p. 73-94, 2015.

MAY MAY, Ezer. ¿Por qué me convertí? ¿Por qué se convirtieron? Los budistas Soka Gakkai de Mérida, Yucatán. Relaciones. Estudios de Historia y Sociedad, Michoacán, v. 37, n. 148bis, p. 205-241, 2016

MELGAR, Dahil. El Japón fragmentado: los nikkei mexicanos y la diáspora japonesa. Humania del Sur, Mérida, ano 6, n. 10, p. 125-134, 2011. 
MORALES ALDANA, Lisette. Conversión, identidad y compromiso en dos grupos budistas japoneses en la ciudad de México. Tesis (Licenciatura en Etnología) ENAH, CDMX, 2002.

MORALES ALDANA, Lisette. De la filosofía a la espiritualidad: perspectiva histórica y caso de estudio de los cambios y las continuidades del budismo en México. Tesis (Maestría en Etnohistoria). ENAH, CDMX, 2006.

MORALES RAMÍREZ, Francisco. Del paganismo a la espiritualidad: prácticas y representaciones sociales del budismo en México, un recuento histórico, 1840-2013. In: XVII Encuentro de la RIFReM, 2014, CDMX. Memorias del XVII Encuentro de la RIFReM, CDMX: Universidad Autónoma Metropolitana, 2014, p. 286.

NUMRICH, Paul. Old Wisdom in the new world: Americanization in two immigrant Theravada Buddhist temples. Knoxville: The University of Tennessee Press, 1996.

OKUBO, Masayuki. The acceptance of Nichiren Shoshu Soka Gakkai in Mexico. Japanese Journal of Religious Studies, Nagoya, v. 18, n. 2-3, p. 189-211, 1991.

OTA, María. Siete migraciones japonesas en México, 1890-1978. México: ColMex, 1982.

SNOW, David; ROCHFORD, E. Burke; WORDEN, Steven; BENFORD, Robert. Frame alignment processes, microbolization and movement participation. American Sociological Review, Washington, v. 51, n. 4, p. 464-481, 1986.

STOLL, David. ¿Pescadores de hombres o fundadores de Imperio? El Instituto Lingüístico de Verano en América Latina. Lima: DESCO, 1985. TABOADA, Hernán G. Un orientalismo periférico: viajeros latinoamericanos, 1786-1920. Estudios de Asia y África, CDMX, v. 23, n. 2, p. 285-305, 1998. 
TWEED, Thomas. Nightstand Buddhists and other creatures: sympathizers, adherents, and the study of religion. In: WILLIAMS, Duncan; QUEEN, Christopher (ed.). American Buddhism. Methods and findings in recent scholarship. Richmond: Curzon, 1999, p. 71-90.

TWEED, Thomas. The American encounter with Buddhism, 1844-1912. Chapel Hill: University of North Carolina Press, 2000.

UNIKEL, Luis. Ensayo sobre una nueva clasificación de población rural y urbana en México. Demografía y Economía, CDMX, v. 2, n. 1, p. 1-18, 1968. UNIKEL, Luis. El desarrollo urbano de México. México: ColMex, 1976.

USARSKI, Frank. Declínio do budismo "amarelo" no Brasil. Tempo Social. Revista de sociología da USP, São Paulo, v. 20, n. 2, p. 133-153, 2008.

USARSKI, Frank. O Dharma verde-amarelo diversificado: quatro perspectivas sobre Budismo brasileiro contemporáneo. In: ALMEIDA, Adroaldo; A. SANTOS, Lyndon de; FERRETTI, Sergio (orgs.). Religião, raça e identidade. São Paulo: Paulinas, 2009, p. 99-113.

VALDERREY, José. Los nuevos movimientos religiosos en el contexto mundial y latinoamericano. Las sectas en la prensa mexicana. México: Editorial Palabra, 1988.

Recebido em: 01/09/2018

Aprovado em: 15/10/2018 